\title{
A recombinant HER2/neu expressing listeria monocytogenes (Lm-LLO) immunotherapy delays metastatic disease and prolongs overall survival in a spontaneous canine model of osteosarcoma - a Phase I clinical trial
}

Josephine S Gnanandarajah', Georges Habineza Ndikuyeze', Julie B Engiles², Anu Wallecha ${ }^{3}$, Nicola Mason ${ }^{1 *}$

From Society for Immunotherapy of Cancer 29th Annual Meeting

National Harbor, MD, USA. 6-9 November 2014

Osteosarcoma (OSA) is an aggressive mesenchymal bone tumor that affects $\sim 3000$ children annually in the USA. Treatment consists of chemotherapy, radiotherapy and radical surgery. Despite treatment, metastatic disease is common and results in $30-40 \%$ mortality within 5 years. Novel therapies that prevent metastatic disease are required to improve outcome. HER2/Neu is a tyrosine kinase receptor belonging to the EGFR family. It is expressed in $\sim 40 \%$ of pediatric OSA and is linked to reduced chemotherapeutic response, high metastatic rates and short overall survival time. Recent reports indicate that HER2/Neu is expressed on OSA tumor initiating cells and that immune targeting of HER $2 / \mathrm{Neu}$ delays metastatic disease.

Large breed dogs spontaneously develop OSA that recapitulates many aspects of pediatric OSA including histologic heterogeneity, aggressive local disease and early metastases. At diagnosis, $95 \%$ of dogs have micrometastatic disease and despite amputation and chemotherapy, the median survival time is 10 months with most dogs euthanized due to progressive metastatic disease. As in pediatric OSA, HER2/Neu is expressed in $~ 40 \%$ of canine appendicular OSA making dogs a relevant model to evaluate the effects of HER2/Neu targeted immune therapy on metastatic disease prevention.

We performed a Phase I clinical trial to evaluate the safety and efficacy of an attenuated, recombinant Listeria monocytogenes $(\mathrm{Lm})$ expressing a chimeric human
HER2/Neu fusion protein (ADXS31-164) to prevent metastatic disease in dogs with HER2/Neu+ appendicular OSA. $L m$ secretes a pore-forming lysin, listeriolysin $\mathrm{O}$ (LLO) that enables it to escape the phagosome and access the class I processing machinery of antigenpresenting cells. As such, recombinant Listeria, engineered to express tumor antigens fused to LLO, induce potent tumor-specific CD8 T cells that mediate tumor regression in murine models. Seventeen dogs with HER2/ Neu+ OSA that had undergone amputation and carboplatin chemotherapy received $1 \times 10^{8}, 5 \times 10^{8}, 1 \times 10^{9}$ or $3 \times 10^{9} \mathrm{CFU}$ of ADXS31-164 intravenously every 3 weeks for three administrations. ADXS31-164-associated toxicities were low grade and transient. Treated dogs failed to develop pulmonary metastatic disease and showed a statistically significant increase in overall survival compared to a historical HER2/Neu+ control group. $14 / 17$ treated dogs are still alive; median survival in HER2/ Neu+ control dogs $(\mathrm{n}=13)$ was 316 days $(\mathrm{p}=0.032)$. ELISpot assays are underway to evaluate ADXS31-164associated HER2/Neu specific immune responses. Our results indicate that ADXS31-164 significantly delays metastatic disease in a clinically relevant, spontaneous model and have important implications for pediatric OSA.

\footnotetext{
Authors' details

${ }^{1}$ University of Pennsylvania, Philadelphia, PA, USA. ${ }^{2}$ University of Pennsylvania, Kennett Square, PA, USA. ${ }^{3}$ Advaxis, Inc, Princeton, NJ, USA.
} 
doi:10.1186/2051-1426-2-S3-P55

Cite this article as: Gnanandarajah et al:: A recombinant HER2/neu expressing listeria monocytogenes ( $L m-L L O)$ immunotherapy delays metastatic disease and prolongs overall survival in a spontaneous canine model of osteosarcoma - a Phase I clinical trial. Journal for ImmunoTherapy of Cancer 2014 2(Suppl 3):P55.

Submit your next manuscript to BioMed Central and take full advantage of:

- Convenient online submission

- Thorough peer review

- No space constraints or color figure charges

- Immediate publication on acceptance

- Inclusion in PubMed, CAS, Scopus and Google Scholar

- Research which is freely available for redistribution

Submit your manuscript at www.biomedcentral.com/submit 